University of Montana

ScholarWorks at University of Montana

$6-2012$

\title{
Transcending Scale Dependence in Identifying Habitat with Resource Selection Functions
}

\author{
Nicholas J. DeCesare \\ Mark Hebblewhite \\ University of Montana - Missoula, mark.hebblewhite@umontana.edu \\ Fiona Schmiegelow \\ David Hervieux \\ Gregory J. McDermid \\ See next page for additional authors
}

Follow this and additional works at: https://scholarworks.umt.edu/wildbio_pubs

Part of the Life Sciences Commons

Let us know how access to this document benefits you.

\section{Recommended Citation \\ DeCesare, Nicholas J.; Hebblewhite, Mark; Schmiegelow, Fiona; Hervieux, David; McDermid, Gregory J.; Neufeld, Lalenia; Bradley, Mark; Whittington, Jesse; Smith, Kirby G.; Morgantini, Luigi E.; Wheatley, Matthew; and Musiani, Marco, "Transcending Scale Dependence in Identifying Habitat with Resource Selection Functions" (2012). Wildlife Biology Faculty Publications. 39. \\ https://scholarworks.umt.edu/wildbio_pubs/39}

This Article is brought to you for free and open access by the Wildlife Biology at ScholarWorks at University of Montana. It has been accepted for inclusion in Wildlife Biology Faculty Publications by an authorized administrator of ScholarWorks at University of Montana. For more information, please contact scholarworks@mso.umt.edu. 
Authors

Nicholas J. DeCesare, Mark Hebblewhite, Fiona Schmiegelow, David Hervieux, Gregory J. McDermid, Lalenia Neufeld, Mark Bradley, Jesse Whittington, Kirby G. Smith, Luigi E. Morgantini, Matthew Wheatley, and Marco Musiani 


\title{
Transcending scale dependence in identifying habitat with resource selection functions
}

\author{
Nicholas J. DeCesare, ${ }^{1,11}$ Mark Hebblewhite, ${ }^{1}$ Fiona Schmiegelow, ${ }^{2}$ David Hervieux,${ }^{3}$ Gregory J. McDermid, ${ }^{4}$ \\ Lalenia Neufeld,${ }^{5}$ Mark Bradley, ${ }^{5}$ Jesse Whittington, ${ }^{6}$ Kirby G. Smith,${ }^{7}$ Luigi E. Morgantini,${ }^{8}$ \\ Matthew Wheatley, ${ }^{9}$ and Marco Musiani ${ }^{10}$ \\ ${ }^{1}$ Wildlife Biology Program, Department of Ecosystem Sciences and Conservation, College of Forestry and Conservation, \\ University of Montana, Missoula, Montana 59812 USA \\ ${ }^{2}$ Department of Renewable Resources, University of Alberta, Edmonton, Alberta T6G $2 \mathrm{H1}$ Canada \\ ${ }^{3}$ Sustainable Resource Development, Government of Alberta, Grande Prairie, Alberta T8V 6J4 Canada \\ ${ }^{4}$ Department of Geography, University of Calgary, 2500 University Drive NW, Calgary, Alberta T2N $1 \mathrm{~N} 4$ Canada \\ ${ }^{5}$ Parks Canada, Jasper National Park, Box 10, Jasper, Alberta T0E 1 EO Canada \\ ${ }^{6}$ Parks Canada, Banff National Park, Box 900, Banff, Alberta T1L 1K2 Canada \\ ${ }^{7}$ Sustainable Resource Development, Government of Alberta, Edson, Alberta T7E 1 T2 Canada \\ ${ }^{8}$ Weyerhaeuser, Forestlands Division, Edmonton, Alberta T5M 3N7 Canada \\ ${ }^{9}$ Provincial Parks Division, Government of Alberta, 131 Civic Center Road, Hinton, Alberta T7V 2 E6 Canada \\ ${ }^{10}$ Faculty of Environmental Design, University of Calgary, 2500 University Drive $\mathrm{NW}$, Calgary, Alberta T2N $1 \mathrm{N4}$ Canada
}

Abstract. Multi-scale resource selection modeling is used to identify factors that limit species distributions across scales of space and time. This multi-scale nature of habitat suitability complicates the translation of inferences to single, spatial depictions of habitat required for conservation of species. We estimated resource selection functions (RSFs) across three scales for a threatened ungulate, woodland caribou (Rangifer tarandus caribou), with two objectives: (1) to infer the relative effects of two forms of anthropogenic disturbance (forestry and linear features) on woodland caribou distributions at multiple scales and (2) to estimate scale-integrated resource selection functions (SRSFs) that synthesize results across scales for management-oriented habitat suitability mapping. We found a previously undocumented scale-specific switch in woodland caribou response to two forms of anthropogenic disturbance. Caribou avoided forestry cut-blocks at broad scales according to first- and second-order RSFs and avoided linear features at fine scales according to third-order RSFs, corroborating predictions developed according to predator-mediated effects of each disturbance type. Additionally, a single SRSF validated as well as each of three single-scale RSFs when estimating habitat suitability across three different spatial scales of prediction. We demonstrate that a single SRSF can be applied to predict relative habitat suitability at both local and landscape scales in support of critical habitat identification and species recovery.

Key words: critical habitat; scale-integrated resource selection function, SRSF; species distribution model; woodland caribou.

\section{INTRODUCTION}

Ecological patterns result from processes occurring at multiple spatial and temporal scales, yet research is typically scale specific (Wiens 1989). Different scales of inference may not carry equal weight in driving patterns most relevant to decision-makers (Levin 1992). Thus, applied ecologists require the elusive ability to focus on "the scales that matter" (Hobbs 2003:233) and ideally to integrate knowledge across scales (Turner et al. 1989). Species-habitat modeling is commonly directed toward applied ecosystem management (Peterson 2006), yet results from such models are necessarily scale specific (Morris 1987, Hobbs 2003, Boyce 2006). The practical

Manuscript received 2 September 2011; revised 3 January 2012; accepted 23 January 2012. Corresponding Editor: E. M. Schauber.

${ }^{11}$ E-mail: nick_decesare@hotmail.com need to generate spatially explicit estimates of habitat importance for applied management, such as the designation of "critical habitat" as required by the U.S. Endangered Species Act (ESA) and Canada Species at Risk Act (SARA), presents significant challenges when interpreting scale-dependent habitat suitability for endangered species (Rosenfeld and Hatfield 2006). Multiple scales of modeling may be required to characterize the full context of habitat relationships (Boyce 2006) and those factors that limit species distributions (Rettie and Messier 2000). However, it remains unclear how to integrate such multi-scale results in applied management, where legal constructs such as critical habitat lack a defined scalar context.

Resource selection has been categorized into an intuitive string of hierarchically nested orders of the behavioral selection process (Johnson 1980, Senft et al. 1987, Meyer and Thuiller 2006). A growing body of 
research has demonstrated widespread evidence for scale dependence in resource selection across taxa (Hobbs 2003, Boyce 2006), yet a means of translating multi-scale resource selection into integrated, spatially explicit treatments of habitat suitability is lacking (Wiens 1989, Wheatley and Johnson 2009). Fine-scale resource selection varies according to fine-scale resource availability (Mysterud and Ims 1998), which is itself the result of broad-scale resource selection. For this reason, spatial extrapolation of fine-scale models alone is not well supported (DeCesare and Pletscher 2006), but broadscale models can be used to establish the spatial context for their extrapolation (Johnson et al. 2004). Below, we demonstrate that attention to this nested relationship in multi-scale sampling design allows the estimation of resource selection models with nested, conditional probabilities of selection within scales. We then synthesize multi-scale conditional probabilities into a single, scale-integrated function with direct application for habitat management.

Assessment of habitat suitability for species conservation should also include identification of limiting factors (Morrison 2001). The importance of habitat factors likely varies with scale, and applied research addressing components of habitat requires cross-scale comparisons of single-scale models to identify the factors that are most limiting (Senft et al. 1987). For example, Rettie and Messier (2000) hypothesized that the fitness consequences of resource selection would decrease at finer spatiotemporal extents. Following this logic, they used multi-scale resource selection analysis to conclude that predation limits populations of a threatened ungulate, woodland caribou (Rangifer tarandus caribou; Rettie and Messier 2000, Gustine et al. 2006), a conclusion further supported by studies of caribou population dynamics (Wittmer et al. 2005). Woodland caribou (hereafter "caribou") were listed as endangered under the ESA in the contiguous United States in 1984, and as threatened (boreal and southern mountain populations) under SARA in Canada in 2002. Federal designation of critical habitat far exceeded legal deadlines in both countries, which may be in some part due to complications in delineating spatial boundaries for a species with complex scale-dependent patterns of resource selection (Environment Canada 2011).

The strength of predation in limiting caribou may be enhanced by multiple sources of anthropogenic landscape change to caribou habitat (Wittmer et al. 2007, Courbin et al. 2009). Commercial forestry subsidizes other ungulate prey with preferred early seral-staged forests and facilitates asymmetric predator-mediated apparent competition and caribou declines (Seip 1992, DeCesare et al. 2010). Anthropogenic linear features such as oil/gas seismic exploration lines (James and Stuart-Smith 2000) or trails (Whittington et al. 2011) also promote caribou mortality by facilitating increased predator (e.g., wolf, Canis lupus) hunting efficiency and spatial overlap. Generally, the impacts of forestry upon woodland caribou are mediated by an increase in the numerical response of wolves (Seip 1992), whereas the impacts of linear features are mediated by an increase in the wolf functional response (James and Stuart-Smith 2000, McKenzie 2006). The numerical and functional responses should theoretically act at broad (i.e., intergenerational) and fine (i.e., intra-generational) spatiotemporal scales, respectively (Hassell 1966). If predators indeed limit caribou dynamics, then the scale at which a given disturbance type affects caribou may be a function of the scale at which it affects the predator response. We hypothesized that the mechanisms of predation affected by forestry (numerical response) and linear features (functional response) drive caribou resource selection at broad and fine scales, respectively.

Here we estimate scale-integrated resource selection functions (SRSFs) across three orders of selection to guide caribou habitat management, and we infer the relative roles of two sources of anthropogenic disturbance, forestry and linear features, in limiting caribou distributions. We used hierarchical sampling to allow the integration of conditional relative probabilities of selection across all three scales. We then tested whether our SRSF's could translate complex, scale-dependent wildlife-habitat relationships into unified and spatially explicit depictions of habitat quality that could be readily incorporated into endangered species recovery planning.

\section{Methods \\ Study area}

We studied woodland caribou from both the Boreal and Southern Mountain federal designations in nine spatially distinct populations (Table 1; A la Pêche, Banff, Brazeau, Little Smoky, Maligne, Narraway, Redrock-Prairie Creek, Redwillow, and Tonquin) within west-central Alberta and eastern British Columbia, Canada. We defined a greater study area polygon that encompassed the study populations and represented the area historically available to caribou at the broadest scale of selection considered. The study area boundary traced natural bioregion (Natural Regions Committee 2006) and watershed boundaries, while excluding areas occupied by neighboring, unsampled, caribou populations in British Columbia, and was supported by historical observations of caribou in currently unoccupied areas (ASRD and ACA 2010).

The greater study area spanned $73566 \mathrm{~km}^{2}$ including $16643 \mathrm{~km}^{2}$ of federally protected areas (National Parks); $7258 \mathrm{~km}^{2}$ and $4813 \mathrm{~km}^{2}$ of provincially protected areas (Provincial Wildland Parks and Wilderness Areas) in Alberta and British Columbia, respectively; and $44854 \mathrm{~km}^{2}$ of remaining lands primarily managed by provincial governments for multiple uses including forestry, oil, and natural gas industries. Protected areas generally included more high-elevation mountainous terrain compared to multiple-use lands, which were predominately boreal conifer foothills. Forestry cutblocks (cut since 1950) comprised between $0 \%$ and $8.9 \%$ 
TABLE 1. Area, percentage of range area covered by cut-blocks, density of linear features (seismic lines and trails), percentage of range area within $250 \mathrm{~m}$ of cut-blocks or linear features, and number of GPS-collared adult females $\left(N_{\mathrm{GPS}}\right)$ for each of nine woodland caribou population annual home ranges in west-central Alberta and eastern British Columbia, Canada, 1998-2009.

\begin{tabular}{|c|c|c|c|c|c|c|}
\hline \multirow[b]{2}{*}{ Population } & \multirow[b]{2}{*}{ Area $\left(\mathrm{km}^{2}\right)$} & \multicolumn{2}{|r|}{ Cut-block } & \multicolumn{2}{|c|}{ Linear feature $\dagger$} & \multirow[b]{2}{*}{$N_{\mathrm{GPS}}$} \\
\hline & & Area $(\%)$ & Area within $250 \mathrm{~m} \mathrm{( \% )}$ & Density $\left(\mathrm{km} / \mathrm{km}^{2}\right)$ & Area within $250 \mathrm{~m} \mathrm{( \% )}$ & \\
\hline A la Pêcheł & 2867 & 1.18 & 3.02 & 0.786 & 28.15 & 26 \\
\hline Banfft & 157 & 0 & 0 & 0.248 & 11.60 & 2 \\
\hline Brazeaut & 388 & 0 & 0 & 0.140 & 6.86 & 10 \\
\hline Little Smoky§ & 1524 & 8.94 & 21.87 & 3.558 & 87.04 & 41 \\
\hline Malignet & 419 & 0 & 0 & 0.280 & 13.92 & 11 \\
\hline Narraway & 2561 & 0.95 & 2.69 & 0.266 & 10.89 & 39 \\
\hline Redrock-Prairie Creek & 4281 & 1.54 & 3.74 & 0.373 & 16.27 & 70 \\
\hline Redwillow & 1723 & 2.63 & 7.19 & 0.599 & 26.16 & 6 \\
\hline Tonquint" & 511 & 0 & 0 & 0.203 & 9.66 & 15 \\
\hline
\end{tabular}

$\dagger$ Linear features in this case included seismic lines and trails and excluded roads.

\$ Federally classified as southern mountain woodland caribou.

$\S$ Federally classified as boreal woodland caribou.

of the area within annual caribou ranges, and the average density of non-road linear features (seismic lines and maintained hiking trails) within annual ranges ranged from 0.1 to $3.6 \mathrm{~km} / \mathrm{km}^{2}$ (Table 1). The functional footprint of disturbance features extends beyond their immediate location (Dyer et al. 2001), and between 0$22 \%$ and $7-87 \%$ of the area of each home range was within $250 \mathrm{~m}$ of a cut-block and non-road linear feature, respectively (Table 1).

\section{Data collection and screening}

We deployed global positioning system (GPS) telemetry collars (Lotek GPS 1000, 2000, 2200, 3300, 4400, and 7000 models; Lotek Wireless, Newmarket, Ontario, Canada) during winters of 1998-2009 on 217 female caribou across nine study populations using helicopter net-gunning (Table 1). Capture protocols were approved by the University of Montana Institutional Animal Care and Use Committee (Animal Use Protocol 059-09MHWB122209), University of Alberta Animal Care Committee (Protocol SCHM-2005-61), and Parks Canada Animal Care Committee (JNP-2009-4052). We targeted adult females for this study and for additional population monitoring objectives, as they represent the segment most responsible for driving overall population dynamics (Eberhardt 2002). Woodland caribou within our study area were partially migratory (McDevitt et al. 2009), and we defined summer (16 May-16 October) and winter (17 October-15 May) seasons for separate analyses according to nonlinear regression analysis of mean migration dates (Appendix A; Bunnefeld et al. 2011).

After removing erroneous locations that were beyond the possible range of study animals (D'Eon et al. 2002), we used the methods of Bjørneraas et al. (2010) to remove 270 error-induced spikes from a data set of 661022 GPS locations. We further filtered and subsampled data to include a uniform data set of locations collected at three- or four-hour fixed intervals for individuals with $>180$ locations per season, corresponding to at least one month of monitoring. We withheld $\geq 20 \%$ of animals for each population-season from model training for external validation, except for the Banff population ( $N=2$ individuals). After these screening procedures the model training data set used for model construction contained 337213 locations for 294 animal-seasons from 181 unique individuals, and the testing data set used for validation contained 85097 locations for 122 withheld animal-seasons. GPS location acquisition success averaged $83 \%$ across individuals, low enough for habitat-induced GPS bias to potentially affect habitat modeling (Frair et al. 2010). We corrected for potential habitat-induced bias of missed fixes using a spatial model of the probability of successfully acquiring a fix $\left(P_{\text {fix }}\right)$ to estimate frequency weights $\left(1 / P_{\text {fix }}\right)$ for inclusion in models (Frair et al. 2010). We estimated $P_{\text {fix }}$ using a model developed with test collars in an overlapping study area (Hebblewhite et al. 2007), though we recognize that estimates of $P_{\text {fix }}$ developed with stationary test collars do not account for the interacting role of animal behavior in driving fix acquisition (Augustine et al. 2011).

\section{Sampling framework}

Analysis of resource selection involves modeling the response (used resources) to spatial heterogeneity (available resources), where the scale of selection is a function of sampling design. We adopt Meyer and Thuiller's (2006) update to Johnson's (1980) terminology and consider three orders of selection: $S_{1}$, first-order population-level selection of seasonal home ranges within the species range; $S_{2}$, second-order individuallevel of selection of seasonal home ranges within population home ranges; and $S_{3}$, third-order individual-level selection of locations within seasonal individual home ranges (Fig. 1). These three orders of selection are conditionally nested (Meyer and Thuiller 2006, Schaefer and Mahoney 2007), though rarely do ecologists take advantage of these nested relationships to integrate inferences across scales.

We used RSFs to translate environmental patterns of resource selection into spatial predicted values proportional to the probability of use for each order of 


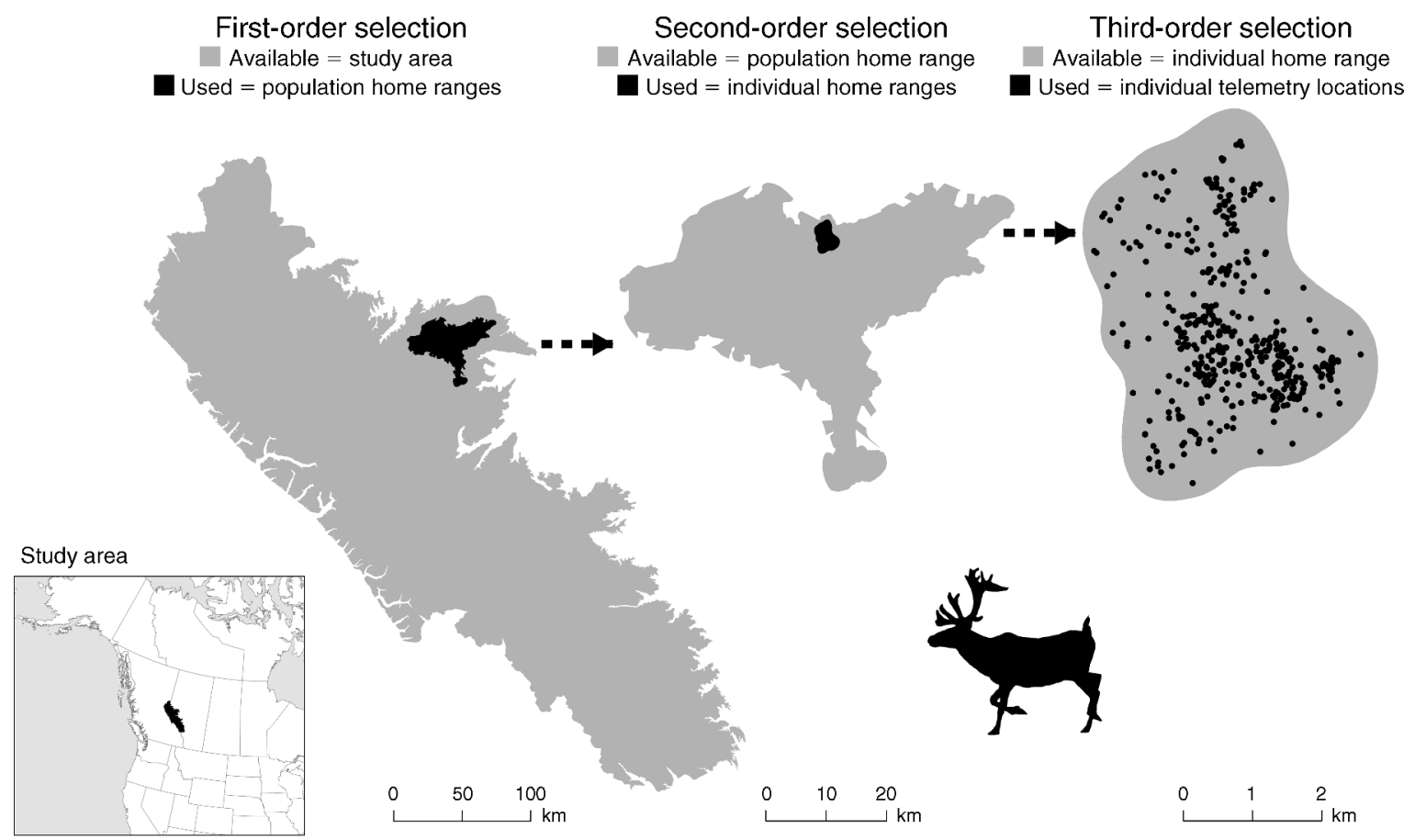

FIG. 1. Schematic of the hierarchically nested sampling design followed for modeling woodland caribou resource selection at three scales of selection in west-central Alberta and eastern British Columbia, Canada, 1998-2009, with a case example for a single season (summer), population (Little Smoky), and individual (F555). For each scale, used and available locations were randomly drawn within black and gray polygons, respectively, except for the third-order scale of selection where GPS telemetry locations (shown in black) defined used locations.

selection (Hirzel and Le Lay 2008). Theoretically, any unit of geographic space $(30 \times 30 \mathrm{~m}$ pixel $)$ within the study area has distinct probabilities of being within the population-level home ranges occupied by caribou $\left(P\left[S_{1}\right]\right)$, being within an individual's home range given that it is within a population home range $\left(P\left[S_{2}\right] \mid P\left[S_{1}\right]\right)$, and being used by a caribou given that it is within an individual's home range $\left(P\left[S_{3}\right] \mid P\left[S_{2}\right]\right)$. Models estimated for multiple scales have been multiplied together as a form of model weighting (Johnson et al. 2004), but the conditional relationship of selection across scales has not been explicitly addressed by integrating models. We sampled used and available locations in a hierarchically nested manner (Fig. 1), which exploited the conditional relationships of selection among scales such that $S_{2}=$ $P\left(S_{2} \mid S_{1}\right)$ and $\mathrm{S}_{3}=P\left(S_{3} \mid S_{2}\right)$. This allowed the estimation of an integrated relative probability of use for a given pixel ( $\left.w_{\text {SRSF }}\right)$ as

$$
\begin{aligned}
w_{\mathrm{SRSF}} & =P\left(S_{1}, S_{2}, S_{3}\right)=P\left(S_{1}\right) \times P\left(S_{2} \mid S_{1}\right) \times P\left(S_{3} \mid S_{2}\right) \\
& =P\left(S_{1}\right) \times P\left(S_{2}\right) \times P\left(S_{3}\right) .
\end{aligned}
$$

We sampled $S_{1}$ selection with a used-unused design (Manly et al. 2002) by drawing a set of random locations within our study area polygon equal in number to the mean number of telemetry locations collected per season ( $N=187928$, Fig. 1). We then designated locations as used or unused distinctly for each of nine caribou populations and two seasons according to whether they fell inside or outside seasonal population home ranges. We considered population home ranges to be a complete depiction of broad-scale caribou use based on $\geq 20$ years of intensive caribou monitoring in this region, which justified our choice of a used-unused sampling framework at the $S_{1}$ scale. For $S_{2}$ and $S_{3}$ selection analyses, we treated individuals as samples of use and applied used-available sampling (Manly et al. 2002, Johnson et al. 2006). We quantified $S_{2}$ selection by treating population seasonal home ranges as available for comparison with used individual seasonal home ranges (Fig. 1). For each population-season, we drew an equal number of random locations within both used (individual) and available (population) home ranges, and we calculated the number of random locations as the mean number of seasonal GPS locations collected per individual. We evaluated $S_{3}$ selection with a usedavailable design by treating random locations within each individual seasonal home range as available for comparison with GPS telemetry-based used locations (Fig. 1). Within available (individual) home ranges we drew sets of random points equal to the number of caribou GPS locations per individual-season.

We estimated population home ranges by buffering GPS-based movement paths (Ostro et al. 1999) with the across-population mean step length (SL) between consecutive three- or four-hour locations during winter 
(mean $\mathrm{SL}=511 \mathrm{~m}$ ) and summer (mean $\mathrm{SL}=625 \mathrm{~m}$ ). To remove the effect of outlying locations, we then defined the population home range as the intersection of a polygon outlining all buffered movement paths and a 95\% fixed-kernel isopleth (calculated with the reference bandwidth [Worton 1989]; Fig. 1). For population-level home ranges, we included unused areas enclosed by movement paths as part of the home range polygon (sensu Ostro et al. 1999); these unused lacunae represented a mean of $8.0 \%$ of the total polygon areas. We estimated seasonal individual home ranges similarly by clipping buffered GPS-based movement paths with both population- and individual-level 95\% kernel estimators (Fig. 1). Because clipped home ranges excluded $5 \%$ of caribou locations, we removed those same locations from the $S_{3}$ analyses to maintain comparable extents of use and availability.

\section{Resource variables}

The RSF models included a suite of topographic (elevation, slope, aspect, topographic position, and distance to water), climatic (percent snow cover and distance to treeline), and vegetative (land cover type and normalized difference vegetation index [NDVI]) explanatory variables. These variables have been found to be important predictors of caribou occurrence in previous caribou ecology research (see Appendix B for details of resource variables; Johnson et al. 2004, Apps and McLellan 2006) and may be considered as surrogates to mechanistic conditions driving caribou space use such as forage quantity and quality, thermal microclimates, and safety from predation (Mitchell and Hebblewhite 2012). We created a base model for each order of resource selection using scale-specific combinations of resource variables (Appendix B).

We then compared the base models to global models, which included both the base resource variables and variables characterizing anthropogenic disturbance, estimated using densities of forestry cut-blocks and linear features (seismic lines and maintained hiking trails; Appendix B). Notably, we did not include roads in the layer of linear features for two reasons: (1) available spatial roads data were digitized with different precision across the provincial boundary, such that much spatial variation in road density was an artifact of data origin, and (2) roads and cut-blocks aligned closely in principal components analysis of disturbance vectors (N. DeCesare, unpublished data), suggesting that the addition of roads captured relatively little additional spatial heterogeneity in overall disturbance patterns. We calculated densities for cut-blocks (proportionate area) and linear features $\left(\mathrm{km} / \mathrm{km}^{2}\right)$ using circular neighborhoods surrounding each raster pixel. We conducted preliminary analyses using density estimates measured at varying radii to identify the most predictive radius for each order of selection (Apps et al. 2001). We pooled the seasonal use-availability data for each order of selection and then estimated a suite of logistic regression models containing both cut-block and linear feature density predictors measured at concentric radii from 1000 to $20000 \mathrm{~m}$ at $1000 \mathrm{~m}$ increments for first- and secondorder selection and from 30 to $5000 \mathrm{~m}$ at 10 and $100 \mathrm{~m}$ increments for third-order selection. We adjusted for unequal sample sizes in the logistic regression models by weighting individuals equally and populations according to their relative area (Table 1). We selected the most predictive radius according to the model with the minimum Akaike Information Criterion $\left(\mathrm{AIC}_{\mathrm{c}}\right.$; Burnham and Anderson 2002), and this radius was then used to characterize both feature densities for subsequent analyses within a given order of selection.

\section{Data analysis}

We used logistic regression to compare resources of used and unused (or available) locations for each order of selection. We included quadratic terms to allow for nonlinear relationships between resource variables and the logit for $S_{1}$ analysis of selection across the greater study area. Quadratic terms were not consistently supported in univariate evaluations of continuous variables at finer scales of selection so we restricted parameterization of continuous variables to linear terms for $S_{2}$ and $S_{3}$ analyses to facilitate averaging coefficients across individuals (Murtaugh 2007). We included only those resource variables with predicted biological relevance at each order of selection (Appendix B) and did not include correlated $(|r|>0.7)$ variables or those with variation inflation factors $>10$ (Montgomery and Peck 1992). When models included the set of land cover type indicator variables we set the most abundant land cover type (closed conifer forest) as the reference category, pooled with any other cover types that represented an average of $<1 \%$ of available points per population-season. For $S_{3}$ analysis involving telemetry locations, we used frequency weights of $1 / P_{\text {fix }}$ to account for habitat-induced biases in GPS fix success (Frair et al. 2010).

We treated resource selection as population-specific, such that we estimated season- and population-specific RSFs for each order, and we did not estimate statistical models of data pooled across populations. For each population $\left(S_{1}\right)$ and individual $\left(S_{2}\right.$ and $\left.S_{3}\right)$ data set, we fit two models: (1) a base model including all topographic, climatic, and vegetative predictor variables and (2) a global model adding anthropogenic predictor variables to the base model. We used $\mathrm{AIC}_{\mathrm{c}}$ to assess the relative support for models including and excluding the effects of anthropogenic features. We averaged AIC weights $\left(w_{\text {AIC }}\right)$ for models with and without anthropogenic effects for each population-season and removed individuals with no measurable coefficients for either disturbance variable (i.e., individuals with cut-block and linear feature densities fixed at 0 within used or available samples) from these averages. For $S_{2}$ and $S_{3}$ orders of selection we then estimated two-stage, populationaveraged, global models (Marzluff et al. 2004, Fieberg 
et al. 2010) using Eqs. 2-4 to estimate inverse variance weighted mean coefficients ( $\beta$; Murtaugh 2007) averaged across individuals $i$ within populations $j$ for each parameter $k$ and season $s$ :

$$
\hat{\hat{\beta}}_{j k s}=\sum_{i=1}^{N} w_{i j k s} \hat{\beta}_{i j k s}
$$

where $w_{i j k s}$ 's are seasonal individual parameter weights estimated as

$$
w_{i j k s}=\frac{1 /\left[\operatorname{SE}\left(\hat{\beta}_{i j k s}\right)\right]^{2}}{\sum_{i=1}^{N}\left(1 /\left[\operatorname{SE}\left(\hat{\beta}_{i j k s}\right)\right]^{2}\right)}
$$

and standard errors are estimated as

$$
\operatorname{SE}\left(\hat{\hat{\beta}}_{j k s}\right)=\sqrt{\frac{\sum_{i=1}^{N} w_{i j k s}\left(\hat{\beta}_{i j k s}-\hat{\hat{\beta}}_{j k s}\right)}{N-1} .}
$$

Standardized coefficients offer one means of comparing the relative effect of predictor variables but their interpretation is complicated when using logistic regression (Menard 2004). Wald statistics (the unstandardized coefficients divided by their estimated standard errors) offer another means for standardized comparison of the relative strength of selection among variables (Goodman 1972) but are sensitive to sample size (Hosmer and Lemeshow 2000). We estimated "standardized Wald statistics," $z_{\text {stdz }}$, for cutblock and linear feature densities by dividing the Wald statistic for each by the average of the absolute values of all Wald statistics estimated for all predictor variables included in global population-season models. These standardized Wald statistics facilitated the comparison of the direction and strength of selection for anthropogenic features across orders of selection where models differed in sample units, sample sizes, and non-anthropogenic resource variables. Positive or negative values of $z_{\text {stdz }}$ indicated selection for increasing or decreasing values in the predictor variable, respectively, while values $>1$ or $<-1$ indicated above average selective response to a given resource variable relative to others in the model. We reestimated $S_{1}$ models similar to $S_{2}$ and $S_{3}$ models, using only linear (no quadratic) terms for continuous variables, for this comparison.

\section{Integrated habitat mapping}

We generated population-level RSFs across three orders of selection, two seasons, and nine populations. More specifically, the used-unused design of $S_{1}$ selection models generated resource selection probability functions (RSPFs), which estimated the probability of use, whereas the used-available designs of $S_{2}$ and $S_{3}$ models generated RSFs, which are proportional to the probabilities of use (Manly et al. 2002). We spatially mapped the per-pixel predicted values $\left(w_{j s}\right)$ for population-level RSPFs and RSFs across the study area at a $30 \times 30 \mathrm{~m}$ resolution. We capped resource values according to the minimum and maximum values sampled for each model to avoid extrapolating predictions beyond the extent of sampled data. We estimated $S_{1}$ RSPF predicted values following Manly et al. (2002), as

$$
w_{j s}(x)=\frac{\exp \left(\beta_{0}+\beta_{1} x_{1}+\beta_{2} x_{2}+\ldots+\beta_{k} x_{k}\right)}{\left(1+\exp \left(\beta_{0}+\beta_{1} x_{1}+\beta_{2} x_{2}+\ldots+\beta_{k} x_{k}\right)\right)} .
$$

We estimated $S_{2}$ and $S_{3}$ RSF predicted values as

$$
w_{j s}(x)=\exp \left(\beta_{1} x_{1}+\beta_{2} x_{2}+\ldots+\beta_{k} x_{k}\right)
$$

and used a linear stretch to rescale RSF predicted values between 0 and 1 (Johnson et al. 2004):

$$
\hat{w}_{j s}=\left(\frac{w_{j s}(x)-w_{\min }}{w_{\max }-w_{\min }}\right) .
$$

For each population-season, we estimated scale-integrated resource selection functions (SRSFs), which integrated selection across orders into a single relative probability, as the product of the conditional relative probabilities using Eq. 1. We stretched SRSFs to range between 0 and 1 according to Eq. 7, and we generated study area-wide weighted average SRSF maps for each season by weighting the predicted values of SRSFs for each population according to the relative proximity between population home ranges and each pixel. Areas within a population's home range were predicted by that population's SRSFs, whereas areas outside of home ranges were estimated with an inverse distance-weighted average across populations. Thus the net contribution of each population's SRSF model to the averaged maps was a function of both the area of that population and its proximity to other populations.

\section{Multi-scale model validation}

We used validation procedures to assess how well single-scale and scale-integrated resource selection models predicted woodland caribou habitat use across different spatial scales. Specifically, we evaluated the spatial predictions of all three single-scale models within both the scales for which they were developed and the remaining two scales, and we assessed the spatial predictions of SRSFs across all scales. First, we spatially extrapolated all $S_{1}, S_{2}, S_{3}$, and SRSF models for each population and season across all three scales of availability: (1) $S_{1}$ study area, (2) $S_{2}$ seasonal population home ranges, and (3) $S_{3}$ seasonal individual home ranges. We sampled predicted values of 50000 random locations within the study area, 10000 random locations within each population home range, and 1000 random locations within each individual home range to characterize the distributions of available predicted values at each spatial scale. We then reclassified each model's predicted values into 10 ordinal, categorical ranks (1-10) of equal area using the percentiles of predicted values for each scale of availability (Boyce et al. 2002). We measured woodland caribou use for each scale identi- 


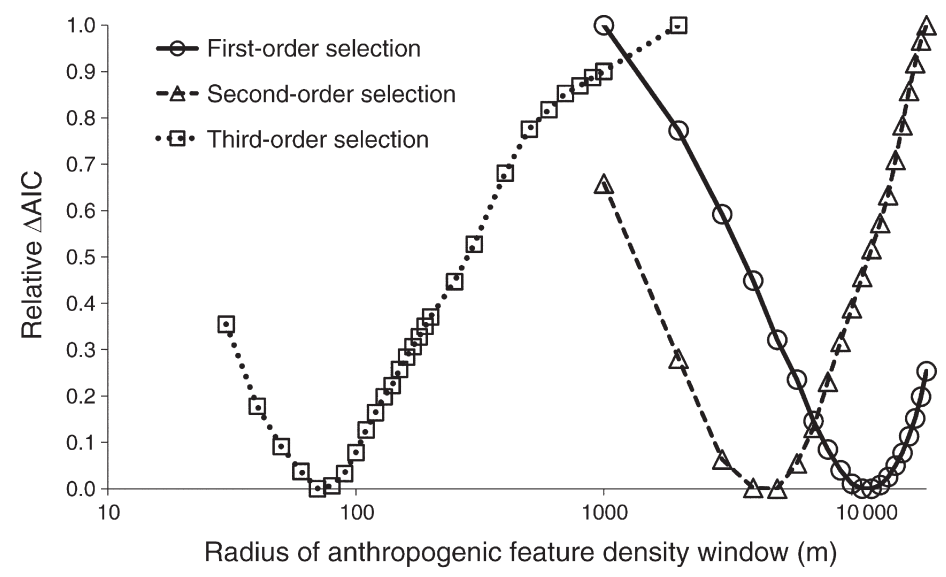

FIG. 2. Relative $\Delta \mathrm{AIC}\left(\Delta \mathrm{AIC} / \Delta \mathrm{AIC} \mathrm{C}_{\max }\right)$ of logistic regression models within three orders of selection assessing the relationship between forestry and linear feature densities measured at varying radii and woodland caribou resource selection patterns pooled across populations and seasons within west-central Alberta and eastern British Columbia, 1998-2009. cally as sampled for model development, using population home ranges, individual home ranges, and individual telemetry locations to represent use for $S_{1}, S_{2}$, and $S_{3}$ scales, respectively.

We validated models by comparing the relative frequencies of woodland caribou use within each category of model predicted values to the ranks of those categories using Spearman rank correlations $\left(r_{\mathrm{S}}\right)$, following Boyce et al. (2002). We initially validated models at all three scales internally by using the same use-availability data that were used for model training. We also validated $S_{2}$ and $S_{3}$ models (excluding the Banff population) externally by using animals completely withheld from model training ( $\geq 20 \%$ of individuals per population, as described above) as a means of robust, external validation with independent data (Fielding and Bell 1997). Last, we used a paired $t$ test comparing $r_{\mathrm{S}}$ among scale-specific and scale-integrated models for each population-season to test whether scale-specific models for each scale validated better than scaleintegrated models.

\section{Results}

Caribou selection response to anthropogenic features was strongest when feature densities were measured within radii of $12000 \mathrm{~m}, 5000 \mathrm{~m}$, and $70 \mathrm{~m}$ for first-, second-, and third-order selection, respectively (Fig. 2). Model weights $\left(w_{\text {AIC }}\right)$ comparing the strength of evidence between our base models and global models suggested a ubiquitous effect of anthropogenic features on caribou resource selection across all three scales of selection (Table 2). The average $w_{\text {AIC }}$ for models including anthropogenic disturbance across individuals and populations declined from 1.00 to 0.908 to 0.801 for first-, second-, and third-order selection, respectively, indicating that responses to human disturbance were clearest at broader scales.

The relative strength of response to cut-block and linear feature densities within models also varied across orders of selection (Table 3, Fig. 3; see Appendix C for full set of coefficients for all RSFs). Population- averaged linear coefficients for cut-block density were negative and stronger than other model coefficients at the broadest scale of first-order selection of population ranges (Fig. 3). Second-order selection of individual home ranges showed weaker but similarly overall negative coefficients for cut-block density, and thirdorder selection within home ranges was inconsistent and weak relative to cut-block density (Fig. 3). Selection of linear feature density showed the opposite effect, being relatively weak and inconsistent at the broader two orders of selection, but consistently negative for thirdorder selection of locations within home ranges (Fig. 3). Thus at broad scales $\left(S_{1}\right.$ and $\left.S_{2}\right)$ caribou avoided areas of high cut-block density and responded inconsistently to linear features, whereas at fine scales $\left(S_{3}\right)$ caribou avoided areas of high linear feature density and responded weakly to cut-blocks.

Scale-integrated RSFs performed well across all three scales according to validation with used telemetry locations. Internal validation of models using resubstituted training data indicated strong predictive capacity when single-scale models were spatially applied to extents for which they were developed $\left(\bar{r}_{s}=0.908\right.$; Table 4). However, extrapolation of single-scale models to other extents revealed inconsistent and relatively poor cross-scale predictive ability of single-scale models $\left(\bar{r}_{s}=\right.$ 0.450; Table 4). On the other hand, scale-integrated resource selection functions (SRSFs; Fig. 4) validated well across all three extents $\left(\bar{r}_{s}=0.900\right.$; Table 4; Fig. 5; Appendices D, E). External validation of $S_{2}$ and $S_{3}$ models with an independent data set of withheld animals showed similar patterns, but slightly poorer fit of both scale-specific $\left(\bar{r}_{s}=0.674\right.$; Table 5$)$ and scale-integrated models $\left(\bar{r}_{s}=0.723\right.$; Table 5$)$ to external data. As a final test of SRSFs, we found no significant difference in the predictive capacity of SRSFs and the relevant scalespecific RSFs at each scale of selection according to paired $t$ tests comparing Spearman rank statistics using both internal $\left(t_{53}=0.345, P=0.366\right)$ and external $\left(t_{53}=\right.$ $-0.684, P=0.751)$ validation data. 
TABLE 2. Average $\mathrm{AIC}_{\mathrm{c}}$ model weights, $w_{\mathrm{AIC}}$, of global woodland caribou resource selection models including variables characterizing anthropogenic feature densities (cut-blocks and linear features) when compared to base models excluding anthropogenic features $\left(1-w_{\text {AIC }}\right)$ across two seasons, nine populations, and three orders of selection, Alberta and British Columbia, 1998 2009.

\begin{tabular}{llll}
\hline \hline & & & \\
\multicolumn{1}{c}{ Population } & & Second-order & Third-order \\
\cline { 2 - 4 } & First-order & & \\
Winter & & 0.926 & 0.865 \\
A la Pêche & 1.00 & 0.707 & 0.281 \\
Banff & 1.00 & 0.898 & 0.832 \\
Brazeau & 1.00 & 1.000 & 0.835 \\
Little Smoky & 1.00 & 0.766 & 0.750 \\
Maligne & 1.00 & 0.955 & 0.751 \\
Narraway & 1.00 & 0.978 & 0.620 \\
Redrock-Prairie Creek & 1.00 & 0.662 & 1.000 \\
Redwillow & 1.00 & 0.929 & 0.837 \\
Tonquin & 1.00 & 0.869 & 0.752 \\
Average & 1.00 & & \\
Summer & & 1.000 & 0.934 \\
A la Pêche & 1.00 & 0.846 & 1.000 \\
Banff & 1.00 & 0.818 & 0.986 \\
Brazeau & 1.00 & 1.00 & 0.991 \\
Little Smoky & 1.00 & 0.998 & 0.951 \\
Maligne & 1.00 & 0.987 & 0.620 \\
Narraway & 1.00 & 0.919 & 0.626 \\
Redrock-Prairie Creek & 1.00 & 1.00 & 0.720 \\
Redwillow & 1.00 & 1.00 & 0.873 \\
Tonquin & 1.00 & 0.952 & 0.856 \\
Average & 1.00 & 0.908 & 0.801 \\
Overall average & 1.00 & & \\
\hline
\end{tabular}

\section{DisCUSSION}

\section{Scale-dependent effects of anthropogenic disturbance}

We found support for our hypothesis whereby anthropogenic disturbance previously linked to predator numerical responses (forestry cut-blocks; Latham et al. 2011) drove first- and second-order caribou resource selection and disturbance linked to predator functional responses (linear features; McKenzie 2006) drove thirdorder caribou resource selection. Predator functional and numerical responses have also been described as intrageneration and intergeneration responses, respectively (Hassell 1966), which suggests a scale-specific nature of predation paralleling that of prey resource selection. Thus, our results support a predator-mediated link between anthropogenic disturbance and woodland caribou distributions across spatiotemporal extents. Corroborating our results, scale-specific effects of predation risk have been found in studies of resource selection by ungulate prey (Gustine et al. 2006, Kittle et al. 2008). Additionally, and with important implications for population dynamics, our results also shed light on the initial findings of Vors et al. (2007), who found twodecade (i.e., intergenerational) time lags between forestry activity and caribou extirpations in Ontario.

We show a scale-dependent trade-off, such that avoidance of forestry cut-blocks must be achieved before fine-scale avoidance of linear features becomes predictive of caribou distribution. Theoretically, we suggest that forestry disturbance presents a relatively greater limitation to woodland caribou (sensu Rettie and Messier 2000). Animals may exhibit resource selection that conveys poor fitness consequences, particularly in recently human-altered systems (Battin 2004). However, for woodland caribou, fitness costs of anthropogenic disturbance are evident. Two independent meta-analyses found the combined footprint of all anthropogenic and natural (fire) disturbances to explain $69 \%$ of the among-population variation in calf recruitment (Environment Canada 2011) and 96\% of the among-population variation in annual population growth rates (Sorensen et al. 2008). Fitness costs have been associated with proximity to (James and StuartSmith et al. 2000, Whittington et al. 2011) and density of linear features (McKenzie 2006), and linear features also may factor into the numerical response (Lee and Boutin 2006). However the ultimate costs to caribou habitat suitability appear relatively less for linear featureinduced changes to the predator functional response (predator kill rate) than forestry-induced changes to the predator numerical responses (predator density; Vucetich et al. 2011).

Vors et al. (2007) observed an extinction debt, or lag time between habitat loss and extirpation, for woodland caribou in Ontario, and they recommended that buffers of intact habitat should surround current population ranges to ensure persistence. Our broad-scale $\left(S_{1}\right)$ selection results support their suggestion that caribou spatial persistence is a function of habitat factors beyond range boundaries and that habitat protection, such as critical habitat designation, 
TABle 3. Population- and season-averaged partial logistic regression coefficients ( $\beta$ ), standard errors (SE), and standardized Wald statistics $\left(z_{\text {stdz }}\right)$ for a subset of predictor variables describing cut-block and linear feature (seismic lines and trails) densities for three scales of resource selection by woodland caribou in west-central Alberta and eastern British Columbia, 1998-2009.

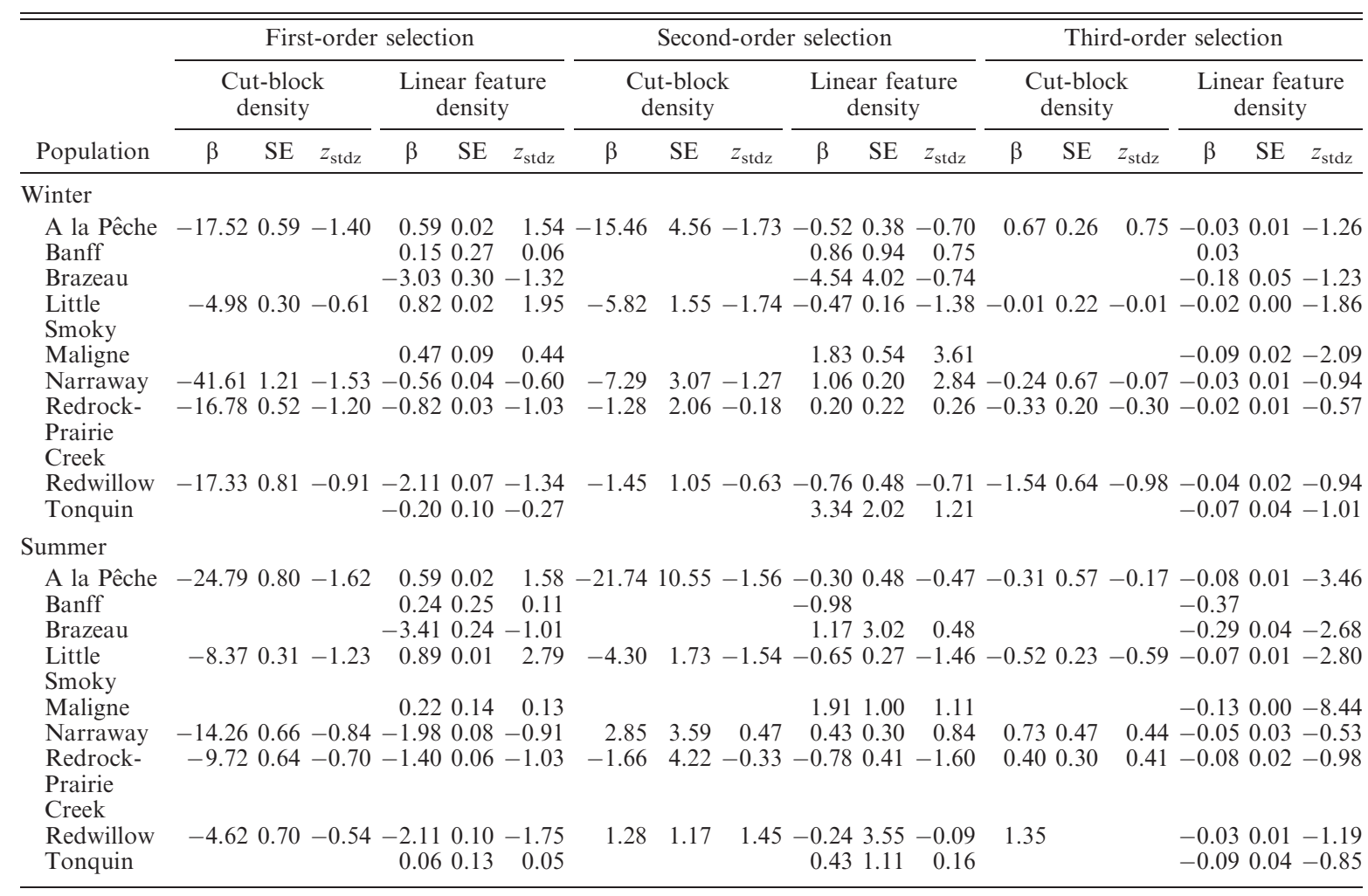

should extend beyond range boundaries themselves. We found broad-scale caribou distribution to be most strongly affected by cut-block density measured within $12 \mathrm{~km}$ radii. This $12-\mathrm{km}$ distance is of the same order of magnitude as previously recommended tolerance distances between caribou and cut-blocks of $9.2 \mathrm{~km}$ (Schaefer and Mahoney 2007), $11.1 \mathrm{~km}$ (Smith et al. 2000), and $13 \mathrm{~km}$ (Vors et al. 2007). However, the area-weighted average ages of cutblocks within our greater study area and within population home ranges were 13 and 7 years, respectively, relative to our average date of animal capture. Thus, additional timelagged effects on predator-prey dynamics and caribou demography may be yet underway, and caribou habitat may take decades to recover.

At the finest scale of selection, we found caribou distribution was most strongly affected by linear feature density measured within $70 \mathrm{~m}$ radii, which seemingly contradicts distances commonly used to represent the zone of influence of linear features upon woodland caribou, such as $250 \mathrm{~m}$ (Dyer et al. 2001, Sorensen et al. 2008) or $500 \mathrm{~m}$ (Environment Canada 2011). We attribute this to two methodological differences between our and previous studies: (1) we aimed to find the distance at which the predictive capacity of a linear feature density variable was maximized, rather than the maximum distance at which avoidance could still be detected (sensu Dyer et al. 2001), and (2) we character- ized linear features as seismic lines and maintained trails but excluded roads, which can affect caribou differently than seismic lines (Dyer et al. 2002). The most predictive radii for measuring feature density at each scale of selection were not consistent when analyses were restricted to particular population-seasons (N. DeCesare, unpublished data), suggesting the realized zone of influence of anthropogenic features may be vary by population, season, and type of disturbance (Dyer et al. 2001, Polfus et al. 2011).

\section{Integrating resource selection functions across scales}

Resource selection functions and other species distribution models serve an applied role of converting ecological niche relationships in environmental space into gradients of predicted habitat suitability across geographic space (Hirzel and Le Lay 2008). A wide range of species distribution modeling techniques are available (Elith and Leathwick 2009) and, in some applied cases, generalized linear models may be outperformed by other techniques (Cianfrani et al. 2010). However, scale dependency is prevalent across all techniques (Hobbs 2003, Barve et al. 2011) and complicates their translation for applied purposes. Scale-specific models yield scale-specific predictions whereas land managers and conservation biologists often require scale-independent maps of habitat (Turner et al. 1989). Though examples of consistent selection patterns 


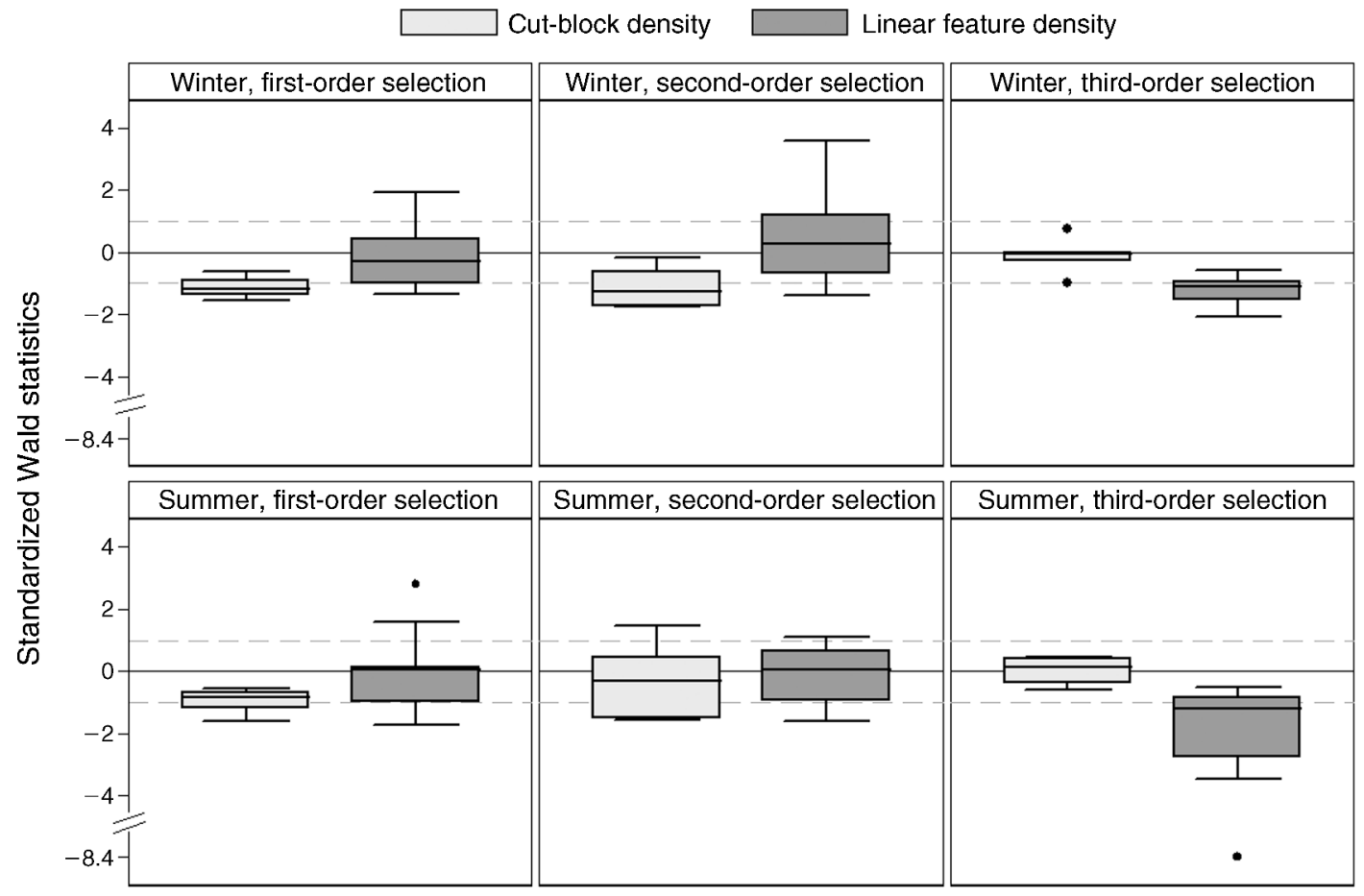

FIG. 3. Box plots of scale- and season-specific standardized Wald statistics $\left(z_{\text {stdz }}\right)$ for predictor variables describing cut-block and linear feature (seismic lines and trails) densities within global logistic regression models for three scales of resource selection by nine woodland caribou populations in west-central Alberta and eastern British Columbia, 1998-2009. The box plots show the medians (center lines), first and third quartiles (enclosed in the boxes), adjacent values (whiskers), and outliers (points) of the estimates. Adjacent values are the lowest and highest observations within 1.5 units of the interquartile range from the first and third quartiles.

across scales do exist (Schaefer and Messier 1995), we use woodland caribou resource selection functions to demonstrate that single-scale models cannot be reliably extrapolated across scales. As a solution, we encourage hierarchically nested sampling and analysis of use-availability data across scales as a means of transcending scaledependence in habitat modeling. Importantly, the product of the resultant conditional probabilities yields a relative probability of use that is integrated across all sampled scales, or an SRSF. Rather than requiring the application of different models to guide conservation efforts directed at different scales, scale-integrated models such as SRSFs provide a single model with predictive capacity across local and landscape scales.

Scale-dependent habitat selection patterns have been well documented for other species of conservation concern, including Capercaille (Tetrao urogallus; Storch 2003), cutthroat trout (Oncorhynchus clarki; Harig and

TABLE 4. Spearman rank correlations $\left(r_{\mathrm{S}}\right)$ and associated $P$ values (in parentheses) correlating woodland caribou resource selection function model predictions and observed frequencies of use using internal, resubstituted training data for validation in west-central Alberta and eastern British Columbia, 1998-2009.

\begin{tabular}{|c|c|c|c|}
\hline Model & Study area & Population home range & Individual home range \\
\hline \multicolumn{4}{|l|}{ Winter } \\
\hline First-order RSPF & $0.907(0.005)$ & $0.768(0.065)$ & $0.270(0.204)$ \\
\hline Second-order RSF & $0.268(0.179)$ & $0.922(0.001)$ & $0.196(0.236)$ \\
\hline Third-order RSF & $0.483(0.070)$ & $0.669(0.184)$ & $0.958(<0.001)$ \\
\hline SRSF & $0.906(0.005)$ & $0.934(0.004)$ & $0.838(0.025)$ \\
\hline \multicolumn{4}{|l|}{ Summer } \\
\hline First-order RSPF & $0.889(0.006)$ & $0.618(0.166)$ & $0.484(0.202)$ \\
\hline Second-order RSF & $0.328(0.143)$ & $0.790(0.069)$ & $0.705(0.169)$ \\
\hline Third-order RSF & $0.075(0.288)$ & $0.542(0.230)$ & $0.981(<0.001)$ \\
\hline SRSF & $0.907(0.004)$ & $0.849(0.040)$ & $0.966(<0.001)$ \\
\hline
\end{tabular}

Notes: Values in italic type indicate results for models being tested at the extents for which they were developed, and values in boldface type indicate results for scale-integrated models. Abbreviations are: RSPF, resource selection probability function; RSF, resource selection functions; and SRSF, scale-integrated resource selection function. 

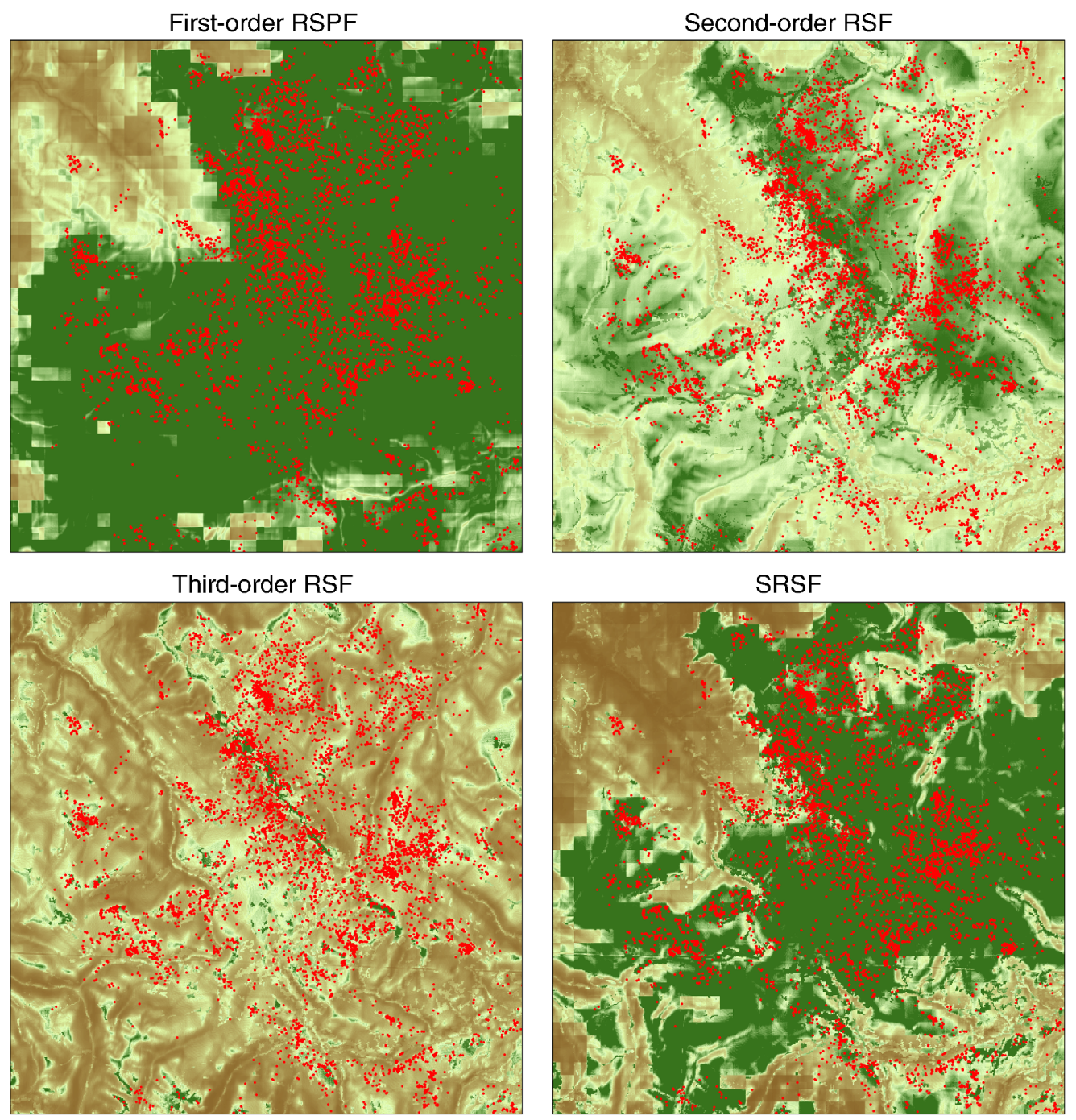

Caribou telemetry locations
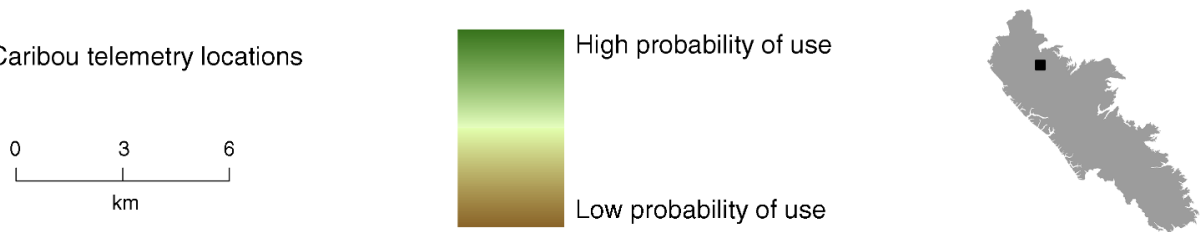

FIG. 4. Sample maps showing predicted values for winter woodland caribou resource selection functions (RSFs) or resource selection probability functions (RSPF), estimated at three scales of selection, a scale-integrated resource selection function (SRSF), and GPS-based telemetry locations for woodland caribou within the Redrock-Prairie Creek population in west-central Alberta, 1998-2009.

Fausch 2002), Canada lynx (Lynx canadensis; Fuller and Harrison 2010), Greater Sage Grouse (Centrocercus urophasianus; Walker et al. 2007), and grizzly bears (Ursus arctos; Ciarniello et al. 2007). Spatial quantification of habitat suitability for such species is a common step in recovery planning, and approaches that integrate selection across scales into single spatial depictions of habitat may best facilitate conservation (Storch 2003). Other researchers wishing to integrate multi-scaled selection models need not follow our exact sampling approach, but must ensure the conditionality of model predicted values. For example, for two models to be hierarchically nested, the predicted values of the broader-scaled model must represent both the probability of being used at the broad scale and the probability of being available at the fine scale. In other words, treating what is available at fine scales as what is used at broad scales ensures a hierarchically nested design (Fig. 1). Designs where the same set of telemetry locations is repeatedly treated as a used sample for comparison with 

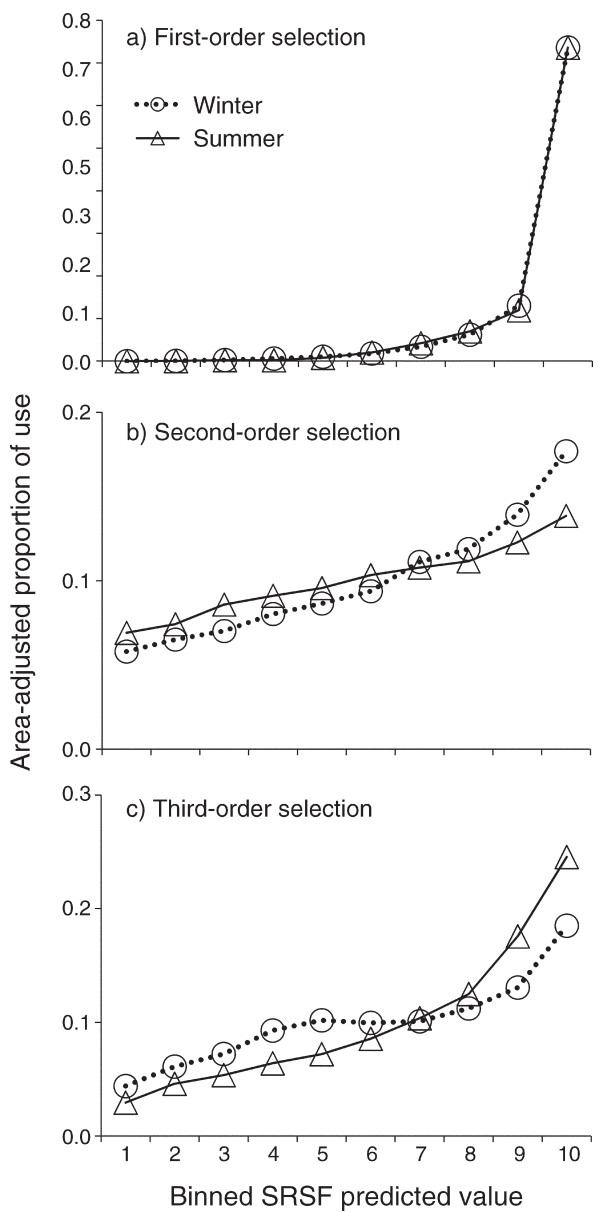

FIG. 5. Area-adjusted proportions of internal validation used locations within each ordinal bin of SRSF predicted values, averaged across nine populations for winter and summer seasonal models depicting woodland caribou resource selection at (a) firstorder $\left(S_{1}\right)$, (b) second-order $\left(S_{2}\right)$, and (c) third-order $\left(S_{3}\right)$ scales of selection in west-central Alberta and eastern British Columbia, 1998-2009. different samples of availability (e.g., Apps et al. 2001, Gustine et al. 2006) will not allow conditional predictions because the used and available locations for each scale are not hierarchically nested.

On average, our patterns for natural covariates were similar to those found in other studies (Appendix C), including broad-scale selection for intermediate elevations and slopes (Johnson et al. 2004), and varying degrees of fine-scale selection for gentle slopes and conifer, shrub, and alpine vegetated land cover types and avoidance of deciduous and rock/ice land cover types depending upon population and season (Johnson et al. 2004, Apps and McLellan 2006, Gustine et al. 2006). We used a proximity-weighted average of the spatial predictions of population-specific SRSFs to estimate multi-population SRSFs for each season (Fig. 6; Appendix F). We did not account for withinpopulation heterogeneity in selection that may occur with partial migration (Hebblewhite and Merrill 2009), and differences in the proportion of migratory individuals between training and testing data sets may explain some instances of poor fit (Appendices D; E; N. DeCesare, unpublished data). Furthermore, distinct selection patterns during potentially important life history states such as calving (Gustine and Parker 2008) or migration (Sawyer and Kauffman 2011) may be muted by the relatively brief proportionate time during which they occurred.

The implications of our SRSF analysis for recovery planning of this species are indicative of generally wideranging benefits of scale-integrated habitat assessment for species conservation. Specifically, our predictive SRSF maps (Fig. 6, Appendix F) may be used for directing broadscale conservation efforts such as protected area strategy and buffer-based area management (Woodroffe and Ginsberg 1998) as well as for fine-scale management of resource extraction practices such as spatial alignment of linear features or forestry cut-blocks. Our models offer a multi-scaled and predictive form of environmental impact assessment, wherein the zone of influence of different

TABLE 5. Spearman rank correlations $\left(r_{\mathrm{S}}\right)$ and associated $P$ values (in parentheses) correlating woodland caribou resource selection function model predictions and observed frequencies of use using external, withheld testing data for validation in west-central Alberta and eastern British Columbia, 1998-2009.

\begin{tabular}{lcc}
\hline \hline \multicolumn{1}{c}{ Model } & Population home range & Individual home range \\
\hline Winter & $0.776(0.124)$ & \\
First-order RSPF & $0.566(0.093)$ & $0.212(0.326)$ \\
Second-order RSF & $0.648(0.079)$ & $0.476(0.273)$ \\
Third-order RSF & $\mathbf{0 . 9 0 3 ( \mathbf { 0 . 0 1 6 } )}$ & $0.933(0.001)$ \\
SRSF & & $\mathbf{0 . 7 9 5}(\mathbf{0 . 0 7 2})$ \\
Summer & $0.223(0.264)$ & \\
First-order RSPF & $0.344(0.331)$ & $0.062(0.224)$ \\
Second-order RSF & $0.397(0.011)$ & $0.456(0.295)$ \\
Third-order RSF & $\mathbf{0 . 4 3 8}(\mathbf{0 . 0 8 7})$ & $0.853(0.015)$ \\
SRSF & $\mathbf{0 . 7 5 5}(\mathbf{0 . 0 7 0 )}$ \\
\hline
\end{tabular}

Notes: Values in italic type indicate results for models being tested at the extents for which they were developed and values in boldface type indicate results for scale-integrated models. 


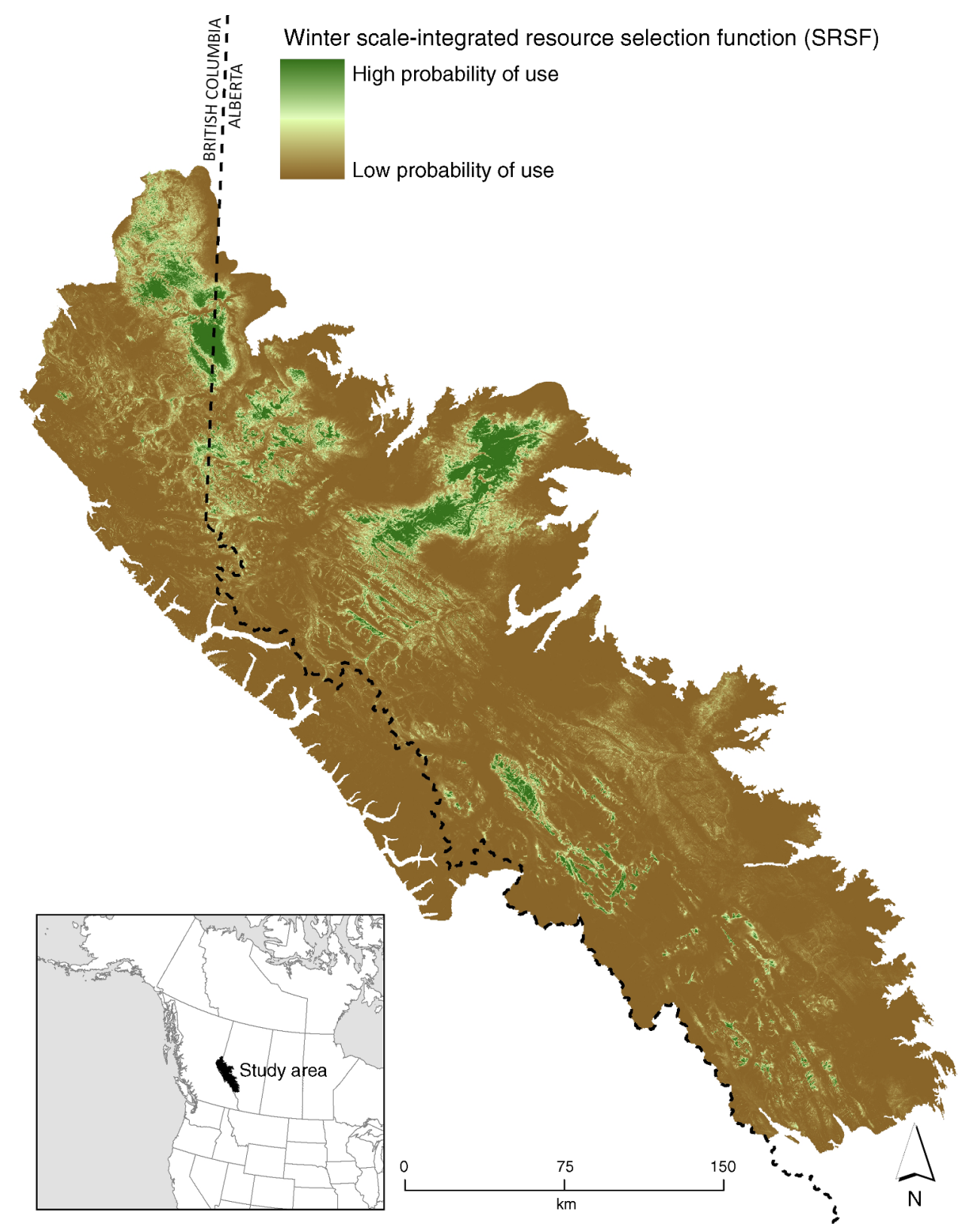

FIG. 6. Example scale-integrated resource selection function (SRSF) for the winter season using inverse proximity weighting to average among the predicted values of nine populations' global models (including both natural and anthropogenic covariate effects) across three scales of selection for woodland caribou in west-central Alberta and eastern British Columbia, 1998-2009.

anthropogenic disturbances (Polfus et al. 2011) can be explored relative to multiple scales of caribou response. These models may also be used to directly estimate the scale-integrated changes in habitat suitability for future extraction or restoration management proposals. Last, given the biological, social, and legal complexities of critical habitat designation as a component of protection under the ESA and SARA, the spatial predictions of our scale-integrated habitat suitability model offer a biological and objective means of delineating explicit boundaries of critical habitat.
Resource selection functions represent habitat suitability as a continuous gradient and ascribe to a nichebased definition of habitat (Gaillard et al. 2010). However, other treatments of spatial habitat suitability, such as legal boundaries of critical habitat or fragmentation models of patch vs. matrix habitat, require Boolean categorization of suitability into habitat and non-habitat. Such ecological boundaries are arguably over-simplified (Strayer et al. 2003, Hirzel and Le Lay 2008), although various techniques are available to estimate threshold predicted values that discretize this 
gradient (Liu et al. 2005). Meaningful categorization may require more than two states of suitability (Hirzel et al. 2006), and thresholds in resource selection may be more evident for some spatial scales than others (Fig. 5). Potential thresholds in habitat suitability may be best determined or validated with fitness-based measures of response (Gaillard et al. 2010). In our study system, further evaluation of the relationship between SRSF predicted values and realized woodland caribou survival and recruitment would best synthesize resource selection, fitness, and persistence measures inherent in the definition of what is critical. Overall, we encourage the incorporation of predictive RSF and SRSF maps within an adaptive conservation framework (Johnson et al. 2004), to be refined with attention to site-specific variation and habitat-demography relationships.

\section{ACKNOWLEDGMENTS}

Financial and other support for our research program was provided by the Alberta Conservation Association, Government of Alberta Department of Sustainable Resource Development, British Columbia Ministry of the Environment, Canadian Association of Petroleum Producers, Canadian Forest Products, Foothills Research Institute, Montana Institute on Ecosystems (as supported by NSF EPSCoR grant EPS1101342), NSERC, Petroleum Technology Alliance of Canada, Parks Canada, Royal Dutch Shell Canada, University of Alberta, University of Calgary, University of Montana, West Central Alberta Caribou Committee, Weyerhaeuser Company, and World Wildlife Fund. Any opinions, findings and conclusions, or recommendations expressed do not necessarily reflect the views of the funding entities listed above. We thank J. Berger, L. S. Mills, W. Peters, D. Pletscher, H. Robinson, and two anonymous reviewers for helpful discussion and reviews of previous versions of this manuscript. We also thank A. Dibb, J. Ficht, S. Hazenberg, D. Hobson, D. Laskin, K. Lisgo, A. McLane, S. Robertson, C. Rohner, M. Russell, D. Seip, M. Sherrington, S. Shirkoff, S. Slater, D. Stepnisky, B. Weckworth, and J. Wilmshurst for their invaluable assistance with data collection and project management.

\section{Literature Cited}

Apps, C. D., and B. N. McLellan. 2006. Factors influencing the dispersion and fragmentation of endangered mountain caribou populations. Biological Conservation 130:84-97.

Apps, C. D., B. N. McLellan, T. A. Kinley, and J. P. Flaa. 2001. Scale-dependent habitat selection by mountain caribou, Columbia Mountains, British Columbia. Journal of Wildlife Management 65:65-77.

ASRD and ACA. 2010. Status of the woodland caribou (Rangifer tarandus caribou) in Alberta: update 2010. Alberta Wildlife Status Report No. 30 (Update 2010). Alberta Sustainable Resource Development and Alberta Conservation Association, Edmonton, Alberta, Canada.

Augustine, B. C., P. H. Crowley, and J. J. Cox. 2011. A mechanistic model of GPS collar location data: implications for analysis and bias mitigation. Ecological Modelling 222:3616-3625.

Barve, N., V. Barve, A. Jiménez-Valverde, A. Lira-Noriega, S. P. Maher, A. T. Peterson, J. Soberón, and F. Villalobos. 2011. The crucial role of the accessible area in ecological niche modeling and species distribution modeling. Ecological Modelling 222:1810-1819.

Battin, J. 2004. When good animals love bad habitats: ecological traps and the conservation of animal populations. Conservation Biology 1482-1491.
Bjørneraas, K., B. Van Moorter, C. M. Rolandsen, and I. Herfindal. 2010. Screening global positioning system location data for errors using animal movement characteristics. Journal of Wildlife Management 74:1361-1366.

Boyce, M. S. 2006. Scale for resource selection functions. Diversity and Distributions 12:269-276.

Boyce, M. S., P. R. Vernier, S. E. Nielsen, and F. K. A. Schmiegelow. 2002. Evaluating resource selection functions. Ecological Modelling 157:281-300.

Bunnefeld, N., L. Börger, B. van Moorter, C. M. Rolandsen, H. Dettki, E. J. Solberg, and G. Ericsson. 2011. A model-driven approach to quantify migration patterns: individual, regional and yearly differences. Journal of Animal Ecology 80:466-476.

Burnham, K. P., and D. R. Anderson. 2002. Model selection and inference: a practical information-theoretic approach. Second edition. Springer-Verlag, New York, New York, USA.

Cianfrani, C., G. Le Lay, A. H. Hirzel, and A. Loy. 2010. Do habitat suitability models reliably predict the recover areas of threatened species? Journal of Applied Ecology 47:421-430.

Ciarniello, L. M., M. S. Boyce, D. R. Seip, and D. C. Heard. 2007. Grizzly bear habitat selection is scale dependent. Ecological Applications 17:1424-1440.

Courbin, N., D. Fortin, C. Dussault, and R. Courtois. 2009. Landscape management for woodland caribou: the protection of forest blocks influences wolf-caribou co-occurrence. Landscape Ecology 24:1375-1388.

DeCesare, N. J., M. Hebblewhite, H. S. Robinson, and M. Musiani. 2010. Endangered, apparently: the role of apparent competition in endangered species conservation. Animal Conservation 13:353-362.

DeCesare, N. J., and D. H. Pletscher. 2006. Movements, connectivity, and resource selection of Rocky Mountain bighorn sheep. Journal of Mammalogy 87:531-538.

D'Eon, R. G., R. Serrouya, G. Smith, and C. O. Kochanny. 2002. GPS radiotelemetry error and bias in mountainous terrain. Wildlife Society Bulletin 30:430-439.

Dyer, S. J., J. P. O'Neill, S. M. Wasel, and S. Boutin. 2001. Avoidance of industrial development by woodland caribou. Journal of Wildlife Management 65:531-542.

Dyer, S. J., J. P. O'Neill, S. M. Wasel, and S. Boutin. 2002. Quantifying barrier effects of roads and seismic lines on movements of female woodland caribou in northeastern Alberta. Canadian Journal of Zoology 80:839-845.

Eberhardt, L. L. 2002. A paradigm for population analysis of long-lived vertebrates. Ecology 83:2841-2584.

Elith, J., and J. R. Leathwick. 2009. Species distribution models: ecological explanation and prediction across space and time. Annual Review of Ecology, Evolution, and Systematics 40:677-697.

Environment Canada. 2011. Scientific assessment to inform the identification of critical habitat for woodland caribou (Rangifer tarandus caribou), boreal population, in Canada: 2011 update. Environment Canada, Ottawa, Ontario, Canada.

Fieberg, J., J. Matthiopoulos, M. Hebblewhite, M. S. Boyce, and J. L. Frair. 2010. Correlation and studies of habitat selection: problem, red herring or opportunity? Philosophical Transactions of the Royal Society B 365:2233-2244.

Fielding, A. H., and J. F. Bell. 1997. A review of methods for the assessment of prediction errors in conservation presence/ absence models. Environmental Conservation 24:38-49.

Frair, J. L., J. Fieberg, M. Hebblewhite, F. Cagnacci, N. J. DeCesare, and L. Pedrotti. 2010. Resolving issues of imprecise and habitat-biased locations in ecological analyses using GPS telemetry data. Philosophical Transactions of the Royal Society B 365:2187-2200.

Fuller, A. K., and D. J. Harrison. 2010. Movement paths reveal scale-dependent habitat decisions by Canada lynx. Journal of Mammalogy 91:1269-1279.

Gaillard, J.-M., M. Hebblewhite, A. Loison, M. Fuller, R. Powell, M. Basille, and B. Van Moorter. 2010. Habitat-performance relationships: finding the right metric at a given spatial scale. 
Philosophical Transactions of the Royal Society B 365:22552265.

Goodman, L. A. 1972. A modified multiple regression approach to the analysis of dichotomous variables. American Sociological Review 37:28-46.

Gustine, D. D., and K. L. Parker. 2008. Variation in the seasonal selection of resources by woodland caribou in northern British Columbia. Canadian Journal of Zoology 86:812-825.

Gustine, D. D., K. L. Parker, R. J. Lay, M. P. Gillingham, and D. C. Heard. 2006. Interpreting resource selection at different scales for woodland caribou in winter. Journal of Wildlife Management 70:1601-1614.

Harig, A. L., and K. D. Fausch. 2002. Minimum habitat requirements for establishing translocated cutthroat trout populations. Ecological Applications 12:535-551.

Hassell, M. P. 1966. Evaluation of parasite or predator responses. Journal of Animal Ecology 35:65-75.

Hebblewhite, M., and E. H. Merrill. 2009. Trade-offs between predation risk and forage differ between migrant strategies in a migratory ungulate. Ecology 90:3445-3454.

Hebblewhite, M., M. Percy, and E. H. Merrill. 2007. Are all global positioning system collars created equal? Correcting habitatinduced bias using three brands in the central Canadian Rockies. Journal of Wildlife Management 71:2026-2033.

Hirzel, A. H., and G. Le Lay. 2008. Habitat suitability modeling and niche theory. Journal of Applied Ecology 45:1372-1381.

Hirzel, A. H., G. Le Lay, V. Helfer, C. Randin, and A. Guisan. 2006. Evaluating the ability of habitat suitability models to predict species presences. Ecological Modelling 199:142-152.

Hobbs, N. T. 2003. Challenges and opportunities in integrating ecological knowledge across scales. Forest Ecology and Management 181:223-238.

Hosmer, D. W., and S. Lemeshow. 2000. Applied logistic regression. Second edition. John Wiley, New York, New York, USA.

James, A. R. C., and A. K. Stuart-Smith. 2000. Distribution of caribou and wolves in relation to linear corridors. Journal of Wildlife Management 64:154-159.

Johnson, C. J., S. E. Nielsen, E. H. Merrill, T. L. McDonald, and M. S. Boyce. 2006. Resource selection functions based on use-availability data: theoretical motivation and evaluation methods. Journal of Wildlife Management 70:347-357.

Johnson, C. J., D. R. Seip, and M. S. Boyce. 2004. A quantitative approach to conservation planning: using resource selection functions to map the distribution of mountain caribou at multiple spatial scales. Journal of Applied Ecology 41:238-251.

Johnson, D. H. 1980. The comparison of usage and availability measurements for evaluating resource preference. Ecology 61:65-71.

Kittle, A. M., J. M. Fryxell, G. E. Desy, and J. Hamr. 2008. The scale-dependent impact of wolf predation risk on resource selection by three sympatric ungulates. Oecologia 157:163-175.

Latham, A. D. M., M. C. Latham, N. A. McCutchen, and S. Boutin. 2011. Invading white-tailed deer change wolfcaribou dynamics in northeastern Alberta. Journal of Wildlife Management 75:204-212.

Lee, P., and S. Boutin. 2006. Persistence and developmental transition of wide seismic lines in the western Boreal Plains of Canada. Journal of Environmental Management 78:240-250.

Levin, S. A. 1992. The problem of pattern and scale in ecology. Ecology 73:1943-1967.

Liu, C., P. M. Berry, T. P. Dawson, and R. G. Pearson. 2005. Selecting thresholds of occurrence in prediction of species distributions. Ecography 28:385-393.

Manly, B. F. J., L. L. McDonald, D. L. Thomas, T. L. McDonald, and W. P. Erickson. 2002. Resource selection by animals: statistical design and analysis for field studies. Second edition. Kluwer Academic Publishers, Dordrecht, The Netherlands.
Marzluff, J. M., J. J. Millspaugh, P. Hurvitz, and M. S. Handcock. 2004. Relating resources to a probabilistic measure of space use: forest fragments and Stellar's Jays. Ecology 85:1411-1427.

McDevitt, A. D., S. Mariani, M. Hebblewhite, N. J. DeCesare, L. Morgantini, D. Seip, B. V. Weckworth, and M. Musiani. 2009. Survival in the Rockies of an endangered hybrid swarm from diverged caribou (Rangifer tarandus) lineages. Molecular Ecology 18:665-679.

McKenzie, H. W. 2006. Linear features impact predator-prey encounters: analysis with first passage time. Thesis. University of Alberta, Edmonton, Alberta, Canada.

Menard, S. 2004. Six approaches to calculating standardized logistic regression coefficients. American Statistician 58:218223.

Meyer, C. B., and W. Thuiller. 2006. Accuracy of resource selection functions across spatial scales. Diversity and Distributions 12:288-297.

Mitchell, M. S., and M. Hebblewhite. 2012. Carnivore habitat ecology: integrating theory and application for conservation. Pages 218-255 in R. A. Powell and L. Boitani, editors. Carnivore ecology and conservation: a handbook of techniques. Oxford University Press, Oxford, UK.

Montgomery, D. C., and E. A. Peck. 1992. Introduction to linear regression analysis. Wiley, New York, New York, USA.

Morris, D. W. 1987. Ecological scale and habitat use. Ecology 68:362-369.

Morrison, M. L. 2001. A proposed research emphasis to overcome the limits of wildlife-habitat relationship studies. Journal of Wildlife Management 65:613-623.

Murtaugh, P. A. 2007. Simplicity and complexity in ecological data analysis. Ecology 88:56-62.

Mysterud, A., and R. A. Ims. 1998. Functional responses in habitat use: availability influences relative use in trade-off situations. Ecology 79:1435-1441.

Natural Regions Committee. 2006. Natural regions and subregions of Alberta. D. J. Downing and W. W. Pettapiece, compilers. Publication No. T/852. Government of Alberta, Edmonton, Alberta, Canada.

Ostro, L. E. T., T. P. Young, S. C. Silver, and F. W. Koontz. 1999. A geographic information system method for estimating home range size. Journal of Wildlife Management 63:748-755.

Peterson, A. T. 2006. Uses and requirements of ecological niche models and related distributional models. Biodiversity Informatics 3:59-72.

Polfus, J. L., M. Hebblewhite, and K. Heinemeyer. 2011. Identifying indirect habitat loss and avoidance of human infrastructure by northern mountain woodland caribou. Biological Conservation 144:2637-2646.

Rettie, W. J., and F. Messier. 2000. Hierarchical habitat selection by woodland caribou: its relationship to limiting factors. Ecography 23:466-478.

Rosenfeld, J. S., and T. Hatfield. 2006. Information needs for assessing critical habitat of freshwater fish. Canadian Journal of Fisheries and Aquatic Sciences 63:683-698.

Sawyer, H., and M. J. Kauffman. 2011. Stopover ecology of a migratory ungulate. Journal of Animal Ecology 80:1078-1087.

Schaefer, J. A., and S. P. Mahoney. 2007. Effects of progressive clearcut logging on Newfoundland caribou. Journal of Wildlife Management 71:1753-1757.

Schaefer, J. A., and F. Messier. 1995. Habitat selection as a hierarchy: the spatial scales of winter foraging by muskoxen. Ecography 18:333-344.

Seip, D. R. 1992. Factors limiting woodland caribou populations and their interrelationships with wolves and moose in southeastern British Columbia. Canadian Journal of Zoology 70:1494-1503.

Senft, R. L., M. B. Coughenour, D. W. Bailey, L. R. Rittenhouse, O. E. Sala, and D. M. Swift. 1987. Large herbivore foraging and ecological hierarchies. BioScience 37:789-799. 
Smith, K. G., E. J. Ficht, D. Hobson, T. C. Sorensen, and D. Hervieux. 2000. Winter distribution of woodland caribou in relation to clear-cut logging in west-central Alberta. Canadian Journal of Zoology 78:1433-1440.

Sorensen, T., P. D. McLoughlin, D. Hervieux, E. Dzus, J. Nolan, B. Wynes, and S. Boutin. 2008. Determining sustainable levels of cumulative effects for boreal caribou. Journal of Wildlife Management 72:900-905.

Storch, I. 2003. Linking a multiscale habitat concept to species conservation. Pages 303-320 in J. A. Bissonette and I. Storch, editors. Landscape ecology and resource management: linking theory with practice. Island Press, Washington, D.C., USA.

Strayer, D. L., M. E. Power, W. F. Fagan, S. T. A. Pickett, and J. Belnap. 2003. A classification of ecological boundaries. BioScience 53:723-729.

Turner, M. G., V. H. Dale, and R. H. Gardner. 1989. Predicting across scales: theory development and testing. Landscape Ecology 3:245-252.

Vors, L. S., J. A. Schaefer, B. A. Pond, A. R. Rodgers, and B. R. Patterson. 2007. Woodland caribou extirpation and anthropogenic landscape disturbance in Ontario. Journal of Wildlife Management 71:1249-1256.

Vucetich, J. A., M. Hebblewhite, D. W. Smith, and R. O. Peterson. 2011. Predicting prey population dynamics from kill rate, predation rate and predator-prey ratios in three wolf-ungulate systems. Journal of Animal Ecology 80:1236-1245.
Walker, B. L., D. E. Naugle, and K. E. Doherty. 2007. Greater sage grouse population response to energy development and habitat loss. Journal of Wildlife Management 71:2644-2654.

Wheatley, M., and C. Johnson. 2009. Factors limiting our understanding of ecological scale. Ecological Complexity $6: 150-159$

Whittington, J., M. Hebblewhite, N. J. DeCesare, L. Neufeld, M. Bradley, J. Wilmshurst, and M. Musiani. 2011. Caribou encounters with wolves increase near roads and trails: a timeto-event approach. Journal of Applied Ecology 48:1535-1542.

Woodroffe, R., and J. R. Ginsberg. 1998. Edge effects and the extinction of populations inside protected areas. Science 280:2126-2128.

Wiens, J. A. 1989. Spatial scaling in ecology. Functional Ecology 3:385-397.

Wittmer, H. U., B. N. McLellan, R. Serrouya, and C. D. Apps. 2007. Changes in landscape composition influence the decline of a threatened woodland caribou population. Journal of Animal Ecology 76:568-579.

Wittmer, H. U., A. R. E. Sinclair, and B. N. McLellan. 2005. The role of predation in the decline and extirpation of woodland caribou. Oecologia 144:257-267.

Worton, B. J. 1989. Kernel methods for estimating the utilization distribution in home-range studies. Ecology $70: 164-168$.

\section{Supplemental Material}

\section{Appendix A}

Defining seasons according to migration parameters (Ecological Archives A022-060-A1).

\section{Appendix B}

Description of GIS-based spatial resource data (Ecological Archives A022-060-A2).

Appendix C

Resource selection functions for three orders of selection, nine populations, and two seasons (Ecological Archives A022-060-A3).

\section{Appendix D}

Validation results per population-season (Ecological Archives A022-060-A4).

\section{Appendix E}

Area-adjusted frequencies of validation locations within ordinal bins of SRSF-predicted values per scale, population, and season (Ecological Archives A022-060-A5).

\section{Appendix F}

Inverse proximity-weighted, among-population average scale-integrated resource selection functions (SRSFs) (Ecological Archives A022-060-A6). 